\title{
Inhibitory Effects of Magnolol on Distal Colon of Guinea Pig in Vitro
}

\author{
Zhao Xiang BiAn, ${ }^{*, a}$ Gen Shui Zhang, ${ }^{a, b}$ Ka Leung Wong, ${ }^{a}$ Xu Guang Hu, ${ }^{a, c}$ Liang LiU, ${ }^{a}$ \\ Zhijun YANG, ${ }^{a}$ and $\mathrm{Min} \mathrm{Li}^{a}$ \\ ${ }^{a}$ School of Chinese Medicine, Hong Kong Baptist University; Kowloon Tong, Hong Kong SAR: ${ }^{b}$ Guangzhou College of \\ Medicine; Guangzhou, 510182 P. R. China: and ${ }^{c}$ Guangzhou College of Pharmacy; Guangzhou, 510006 P. R. China. \\ Received September 21, 2005; accepted December 27, 2005
}

The influence of plant product magnolol $\left(0-100 \mu_{\mathrm{M}}\right)$ on the contractile activity of isolated colonic muscle strips in guinea pig and related mechanism were investigated. Magnolol did not affect the base tone of colon muscle strips, but it dose-dependently inhibited $40 \mathrm{~mm} \mathrm{KCl-,} 1 \mu_{\mathrm{M}}$ carbachol (CCh)- and $10 \mu_{\mathrm{M}}$ serotonin (5-HT)induced contractions at concentrations higher than $10 \mu \mathrm{M}$. And also, magnolol inhibited the 5-HT- or CCh-induced muscle contraction in calcium-free buffer. Furthermore, magnolol inhibited the KCl-induced contraction under the condition of procaine. In addition, inhibition rate of nifedipine plus magnolol on muscle strips was lower than that of nifedipine alone. Moreover, magnolol dose-dependently decreased the velocity of pellet propulsion in the concentration range of $0.1-10 \mu \mathrm{M}$, and totally inhibited pellet propulsion at the concentration higher than $30 \mu \mathrm{M}$. Thus, it can be concluded that magnolol may 1) block receptor-operated cation channels and the voltage dependent $\mathrm{Ca}^{2+}$ channel, and 2) inhibit calcium release from the sarcolemmal membrane (SR) through blocking Ins $\mathrm{P}_{3}$-sensitive and ryanodine-sensitive pathways. This explains, at least partially, that Cortex magnoliae officinalis exerts therapeutic effects on gastrointestinal disease through relaxation of GI tract smooth muscles.

Key words magnolol; smooth muscle; $\mathrm{Ca}^{2+}$ channel

Magnolol (MAG), 5,5-Di-2-propenyl-[1,1-biphenyl]-2,2diol (Fig. 1), is the major phenolic compound purified from the medical plant Cortex magnoliae officinalis, ${ }^{1)}$ which has been used for lower gastrointestinal disorders (e.g., diarrhea, constipation) in Traditional Chinese Medicine for long time. ${ }^{2)}$ Major findings about the pharmacological activity of MAG involved: 1) inhibition of the respiratory burst in formylmethionyl-leucyl-phenylalanine activated neutrophils ${ }^{3)}$; 2) suppression of the overproduction of nitric oxide and tumor necrosis factor (TNF)- $\alpha$ in lipopolysaccharide activated macrophages ${ }^{4}$; 3 ) protection of transplanted organs from lipid peroxidation ${ }^{5}$; 4) prevention of chemical hypoxia in cortical neurons of rats ${ }^{6}$; and 5) antioxidative effect on neutrophil adhesion in vitro and in vivo in rats, ${ }^{7-9)}$ Furthermore, MAG has previously been reported to inhibit smooth muscle contraction in porcine trachea, with possible mechanism of blockade of calcium influx through voltage dependent $\mathrm{Ca}^{2+}$ channels. ${ }^{10)}$ Recently, one study reported that MAG can inhibit contractility of the upper gastrointestinal tract smooth muscles of isolated gastric fundus strips of rats and isolated ileum of guinea pigs with a calcium-antagonistic effect, ${ }^{11)}$ but no research have been done about MAG on the lower gastrointestinal tract. The characteristics of different parts of the gastrointestinal tract are not the same, especially in terms of motility ${ }^{12)}$ permeability, ${ }^{13)}$ and response to calcium manipulation. ${ }^{14)}$ Thus, it is necessary to study the effect of MAG on colon, in order to understand the pharmacological action of MAG in lower gastrointestinal disorder.

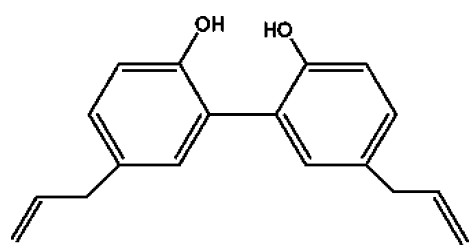

Fig. 1. Molecular Structure of Magnolol
In this study, pharmacological effects of MAG on muscle strips isolated from distal colon of guinea pig were investigated with the presence of activators and inhibitors of muscle contraction, and isolated colon segments of guinea pig were used to test the effect of MAG on the velocity of artificial pellet propulsion.

\section{MATERIALS AND METHODS}

Tissue Preparation Male guinea pigs $(200-250 \mathrm{~g})$ were fasted for $24 \mathrm{~h}$, and then sacrificed by stunning and cervical dislocation, and $2-\mathrm{cm}$ pieces of the colon were dissected from the colon segment 1.5 to $2 \mathrm{~cm}$ from anus. Luminal contents were washed out with Krebs-bicarbonate buffer. The segments were then opened along the mesenteric border, cut into $10 \mathrm{~mm} \times 4 \mathrm{~mm}$ strips approximately along the circular and longitudinal axis individually and transferred into cold Krebs-bicarbonate buffer. The mucosa was carefully dissected away to expose the muscularis externa. Tissues were mounted for tension recording and allowed to equilibrate for $1-2 \mathrm{~h}$ in $10-\mathrm{ml}$ chambers containing Krebs-bicarbonate buffer $\left(118 \mathrm{~mm} \mathrm{NaCl}, 4.8 \mathrm{~mm} \mathrm{KCl}, 1.2 \mathrm{mM} \mathrm{KH}_{2} \mathrm{PO}_{4}\right.$, $1.2 \mathrm{~mm} \mathrm{MgSO}_{4}, 2.5 \mathrm{~mm} \mathrm{CaCl}_{2}, 25 \mathrm{~mm} \mathrm{NaHCO}_{3}$ and $11 \mathrm{~mm}$ Glucose, $\mathrm{pH} 7.4$, at $37^{\circ} \mathrm{C}$ ), and saturated with $95 \% \mathrm{O}_{2}$ and $5 \% \mathrm{CO}_{2}$. The colonic longitudinal muscle strips (LMS) and circular muscle strips (CMS) were initially maintained at $0.5 \mathrm{~g}$ tension and equilibrated for $60 \mathrm{~min}$. The bath solution was replaced every $20 \mathrm{~min}$ to keep the solution fresh during equilibration.

Measurement of Contractile Activity The mechanical responses in preparations were recorded with an isometric transducer (AD instruments, Australia) and a polygraph. For the MAG induced inhibition of preparations, responses were calculated as percentages of the contraction induced by different stimulators, such as serotonin $(5-\mathrm{HT}), \mathrm{KCl}$ or carhachol $(\mathrm{CCh})$, which was applied at the beginning of the experiment for calibration. 
Measurement of Velocity of Pellet Propulsion (VPP) Male guinea pigs $(200-250 \mathrm{~g})$ were fasted for $24 \mathrm{~h}$, sacrificed by stunning and cervical dislocation, and then the whole colon was obtained. The proximal 3 to $4 \mathrm{~cm}$ and distal 1 to $2 \mathrm{~cm}$ were discarded. The remaining pellet-containing portion was incubated in Krebs-bicarbonate medium at $37^{\circ} \mathrm{C}$ for $30 \mathrm{~min}$, to allow spontaneous evacuation of the pellets. Each distal colon was cut into two equal segments and secured with pins placed at intervals through the attached mesentery. After 30 min equilibration, an artificial fecal pellet similar in shape and size to colonic fecal pellets (10-mm long $\times 2$-mm wide) was inserted into the oral end of the segment to calculate VPP. It was calculated on the basis of the time taken by a pellet to transverse a $3-\mathrm{cm}$ segment of isolated colon. The basal VPP was first determined using three successive pellets inserted at $5 \mathrm{~min}$ intervals. The segments were allowed to equilibrate again in fresh buffer for $30 \mathrm{~min}$. And then MAG was added into buffer directly to test the effect on VPP. The results of MAG on VPP were expressed as percentage of basal velocity in millimeters per second. ${ }^{15)}$

Protocol of Experiments. Test One: Effects of MAG on Muscle Strip Contractions Induced by 5-HT, CCh and KCl Effects of MAG $(0 \mu \mathrm{M}, 1 \mu \mathrm{M}, 10 \mu \mathrm{M}, 30 \mu \mathrm{M}, 100 \mu \mathrm{M})$ on muscle strip contractions induced by three different stimulants $(10 \mu \mathrm{m}$ serotonin, $1 \mu \mathrm{M} \mathrm{CCh}$ and $40 \mathrm{~mm} \mathrm{KCl})$ were tested separately. The procedures were as follows: muscle strips were treated with $40 \mathrm{~mm} \mathrm{KCl,} 10 \mu \mathrm{M} 5$-HT and $1 \mu \mathrm{M}$ $\mathrm{CCh}$ separately at first, the contraction results of each stimulant were recorded as the baseline. After washout for $30 \mathrm{~min}$, the strips were pre-exposed to MAG with different concentration separately for $5 \mathrm{~min}$, and activated by $10 \mu \mathrm{M} 5-\mathrm{HT}$, $1 \mu \mathrm{M} \mathrm{CCh}$ or $40 \mathrm{~mm} \mathrm{KCl}$ respectively again. The muscle strip contraction were recorded and compared with respective calibration.

Test Two: Effects of MAG on Muscle Strip Contractions Induced by 5-TH and $\mathrm{CCh}$ in Calcium Free Krebsbicarbonate Buffer Effects of MAG on muscle strip contractions induced by 5 -HT or $\mathrm{CCh}$ in the calcium-free media were tested respectively. The procedure was same as that of test one, but no calcium existed in the buffer. This experiment aimed to study the effect of $100 \mu \mathrm{M}$ MAG on $1 \mu \mathrm{M}$ CCh-induced or $10 \mu \mathrm{M} 5$-HT-induced LMS contractions in calcium-free Krebs-bicarbonate buffer. LMS were treated with CCh or 5-HT for 1 min first, then treated with MAG for 5 min respectively, and finally activated by $\mathrm{CCh}$ or 5 -HT again.

Test Three: Effects of MAG Plus Nifedipine on The Contraction of Muscle Strips Longitudinal strips were pretreated with $0.5 \mu \mathrm{M}$ nifedipine or $0.5 \mu \mathrm{M}$ nifedipine plus $100 \mu \mathrm{M}$ MAG respectively. Then muscle strips were contracted by $40 \mathrm{~mm} \mathrm{KCl}$. The outcomes of contraction were compared with that of pretreatment with $100 \mu \mathrm{M}$ MAG.

Test Four: Effect of MAG on KCl-Induced Contraction with $1 \mathrm{~mm}$ Procaine Muscle strips were exposed to $10 \mathrm{~mm}$ procaine for $1 \mathrm{~min}$ and then contracted by $40 \mathrm{~mm} \mathrm{KCl}$ for calibration, and the results were recorded as baseline for control. After 15 min washout until the muscle strips returned to steady state, MAG $(0,30,100 \mu \mathrm{M})$ and $10 \mathrm{~mm}$ procaine were added into organ bath chamber for $1 \mathrm{~min}$, followed by $40 \mathrm{~mm}$ $\mathrm{KCl}$ to induce contraction. The contraction outcomes were compared with respective baselines and calculated as per- centages of the contractile response obtained in calibration.

Test Five: Effect of MAG on Velocity of Pellet Propulsion MAG was directly added to the organ bath solution, with different final concentrations $(0 \mu \mathrm{M}, 0.1 \mu \mathrm{M}, 1 \mu \mathrm{M}$, $10 \mu \mathrm{M})$ in the organ bath solution respectively, and the velocity of pellet propulsion was tested separately.

Drugs and Solutions MAG ( $99 \%$ purity), purchased from the National Institute for the Control of Pharmaceutical \& Biological Products of P. R. China, was dissolved in dimethyl sulfoxide (DMSO). CCh, 5-HT, nifedipine, thapsigargin and procaine were purchased from Sigma Chemical Co. (Sigma-Aldrich China Inc). The concentrations of drugs described in this paper refer to the final bath concentrations.

Statistical Analysis Results were expressed as mean \pm S.D. with the number of experiments given in parentheses. For the comparison of data, paired or unpaired Student's $t$ tests or analysis of variance (ANOVA) were used where applicable. Differences were considered to be significant when $p \leqq 0.05$.

\section{RESULTS}

Test One: Inhibitory Effects of MAG on 5-HT-, CChor KCl-Induced Contraction $(n=8)$ in the Guinea Pig Isolated Colon Muscle Strips MAG did not influence the baseline of preparations (data were not shown in this paper). As shown in Figs. 2a, b and c, pre-exposure of the preparations to $1 \mu \mathrm{M}$ MAG for 1 min cannot significantly inhibit KCl-, 5-HT- or CCh-induced LMS and CMS contraction, while pre-exposure to MAG at concentrations higher than $10 \mu \mathrm{m}$ dose-dependently inhibited 5-HT-, KCl- or CCh-induced LMS and CMS contraction. The inhibition rates of MAG at concentrations of $10 \mu \mathrm{M}, 30 \mu \mathrm{m}$ or $100 \mu \mathrm{m}$ on 5-HTinduced contraction of LMS were $12 \%, 28 \%$ and $45 \%$ respectively, while on CMS they were $22 \%, 29 \%$ and $40 \%$, respectively. As for CCh-induced contraction of LMS, the inhibitory rates of MAG at concentrations of $10 \mu \mathrm{M}, 30 \mu \mathrm{M}$ or $100 \mu \mathrm{m}$ were $12 \%, 21 \%$ and $27 \%$ respectively, while for CMS they were $23 \%, 30 \%$ and $36 \%$ respectively. The inhibition rate of MAG at concentrations of $10 \mu \mathrm{M}, 30 \mu \mathrm{M}$ or $100 \mu \mathrm{M}$ on KCl-induced contractions of LMS were $15 \%$, $30 \%$ and $41 \%$ respectively, while for CMS they were $22 \%$, $34 \%$ and $39 \%$ respectively.

Test Two: Inhibitory Effects of MAG on Contractions of the Guinea Pig Isolated Colon Muscle Strips Induced by 5-HT-, CCh-Induced Contraction in Calcium-Free Buffer $(\boldsymbol{n}=\mathbf{8})$ As shown in Fig. 3a, MAG dose-dependently inhibited the 5-HT-induced contraction in LMS in calcium-free buffer. The inhibitory rate of MAG at the concentration of $1 \mu \mathrm{M}, 10 \mu \mathrm{m}, 30 \mu \mathrm{m}$ or $100 \mu \mathrm{m}$ were $38 \%, 63 \%$, $76 \%$ and $92 \%$ respectively. Fig. $3 \mathrm{~b}$ showed that $100 \mu \mathrm{M}$ MAG inhibited CCh-induced LMS contraction in calcium-free buffer, with the inhibitory rate $36 \%$.

Test Three: Inhibitory Effect of MAG vs. MAG Plus Nifedipine on KCl-Induced Contraction in the Guinea Pig Isolated Colon Muscle Strips $(n=8)$ Nifedipine, a classic calcium channel blocker, can decrease the intracellular calcium concentration $\left(\left[\mathrm{Ca}^{2+}\right]_{\mathrm{i}}\right)$. As shown in Fig. 4, when LMS was pre-exposed to $1 \mu \mathrm{M}$ nifedipine alone or $1 \mu \mathrm{M}$ nifedipine plus $100 \mu \mathrm{M}$ MAG separately, their inhibition rates on $40 \mathrm{~mm} \mathrm{KCl}$-induced contraction were $92 \%$ and $71 \%$. 
(a)

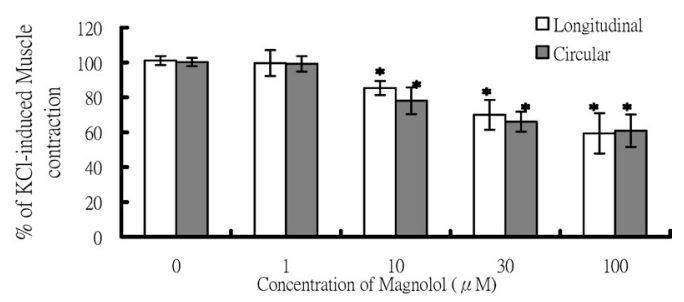

(b)

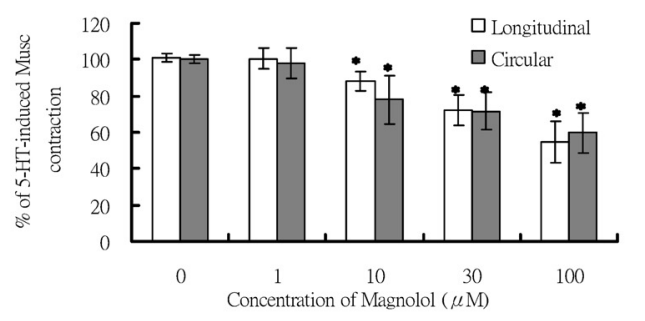

(c)

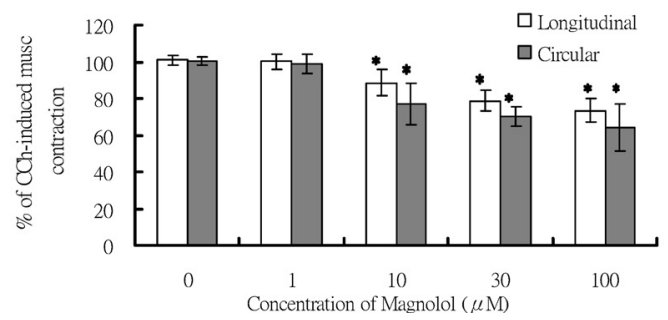

Fig. 2. Mag-Induced Inhibition of 5-HT, $\mathrm{CCh}$, and $\mathrm{KCl}$-Induced Muscle Strips Contraction

Graph showing the concentration-related inhibitory effects of pretreatment with MAG $(1-100 \mu \mathrm{M})$ on the submaximal contractions induced by $\mathrm{KCl}(40 \mu \mathrm{M}, n=8$, Fig. 2a), 5-HT(10 $\mu \mathrm{M}, n=8$, Fig. 2b) and CCh $(1 \mu \mathrm{M}, n=8$, Fig. $2 \mathrm{c})$ in the guinea pig. Data are shown as means \pm S.E. $*$ Significance at $p<0.05$ vs. $0 \mu$ M magnolol (blank), $n=8$.

There were significant difference $(p<0.05)$ between two groups. As showed in Fig. 2a and Fig. 4, the inhibition rate of $100 \mu \mathrm{M}$ MAG on KCl-induced contractions of LMS were $41 \%$, with significant difference in contrast with that of nifedipine or MAG plus nifedipine $(p<0.05)$.

Test Four: Inhibitory Effect of MAG on KCl-Induced Contraction with $1 \mathrm{~mm}$ Procaine Condition $(\boldsymbol{n}=\mathbf{8})$ The effect of MAG on $\mathrm{KCl}$-induced contraction under pretreatment with $1 \mathrm{~mm}$ procaine, a ryanodine receptor inhibitor, was investigated. As shown in Fig. 5, MAG significantly inhibited the contraction induced by $40 \mathrm{mM} \mathrm{KCl}$ between $1-100 \mu \mathrm{M}$ concentrations.

Test Five: Inhibitory Effect of MAG on Velocity of Pellet Propulsion $(\boldsymbol{n}=\mathbf{6})$ As shown in Fig 6, MAG dose-dependently decreased the VPP at the concentration range of $0.1-10 \mu \mathrm{M}$. At the concentration higher than $30 \mu \mathrm{M}$, MAG totally inhibited pellet propulsion in colon segment.

\section{DISCUSSION}

The present study found that 1) MAG did not affect the base tone of colon muscle strips, but dose-dependently inhibited high $\mathrm{K}^{+}$-, CCh- and 5-HT-induced contractions at concentrations higher than $10 \mu \mathrm{M}$; and 2) MAG inhibited CCh-

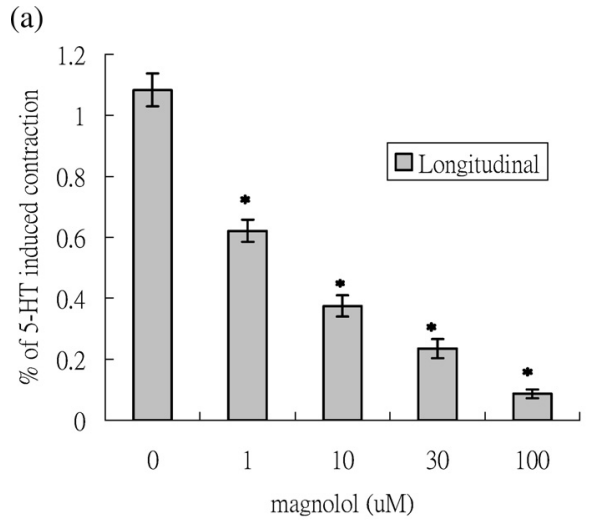

(b)

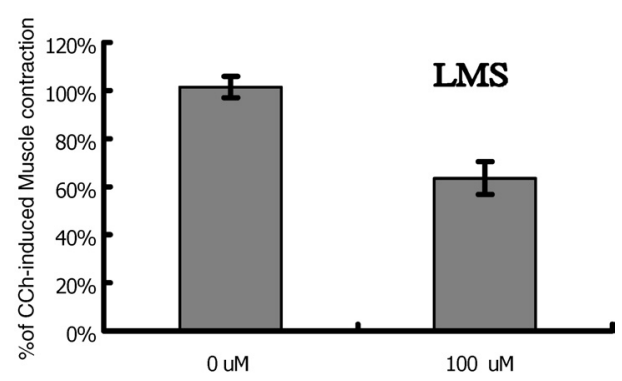

Fig. 3. Mag-Induced Inhibition of 5-HT, Cch-Induced Muscle Strips Contraction in Calcium-Free Krebs-Bicarbonate Buffer

Graph showing the concentration-related inhibitory effects of pretreatment with MAG $(1-100 \mu \mathrm{M})$ on the submaximal contractions induced by 5 -HT $(10 \mu \mathrm{M}, n=8$, Fig. $3 \mathrm{a})$ in the guinea pig and inhibitory effects of pretreatment with MAG $(100 \mu \mathrm{M})$ on the submaximal contractions induced by CCh $(1 \mu \mathrm{M}, n=8$, Fig. $3 \mathrm{~b})$ in the guinea pig. Data are shown as means \pm S.E. $*$ Significance at $p<0.05 v s .0 \mu \mathrm{M}$ magnolol (blank).

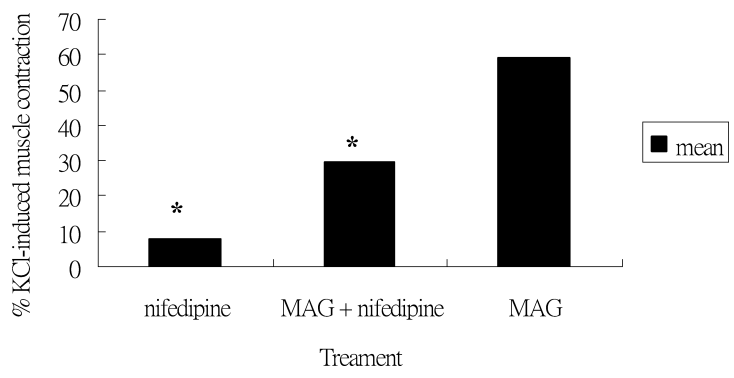

Fig. 4. Inhibitory Effect of Magnolol on $\mathrm{KCl}(40 \mu \mathrm{M})$-Induced Contraction of LMS in Presence or Absence of Nifedipine

Inhibition rate of $1 \mu \mathrm{M}$ nifedipine alone, $1 \mu \mathrm{M}$ nifedipine plus $100 \mu \mathrm{M}$ MAG and $100 \mu \mathrm{M}$ MAG alone on $40 \mu \mathrm{M} \mathrm{KCl-induced} \mathrm{contraction} \mathrm{were} 92 \%, 71 \%$ and $41 \%$ respectively. Data are shown as means \pm S.D. $*$ Significance at $p<0.05 v s$. magnolol alone, $n=8$.

and 5-HT-induced contractions in calcium-free Krebs-bicarbonate buffer; 3) the inhibition rate of nifedipine plus MAG on LMS contractions was higher than that of MAG, but lower than that of nifedipine alone on LMS; 4) MAG dosedependently inhibited KCl-induced contraction under $1 \mathrm{~mm}$ procaine condition; and 5) MAG dose-dependently decreased the VPP at the concentration range of $0.1-10 \mu \mathrm{M}$, and totally inhibited pellet propulsion in colon segment at the concentration higher than $30 \mu \mathrm{M}$. The data indicate that MAG not only blocked voltage dependent $\mathrm{Ca}^{2+}$ channel and nonselective cation channel, but also inhibiting calcium release from the sarcolemmal membrane (SR) via inositol trisphosphate $\left(\mathrm{InsP}_{3}\right)$-sensitive and ryanodine-sensitive receptors. 


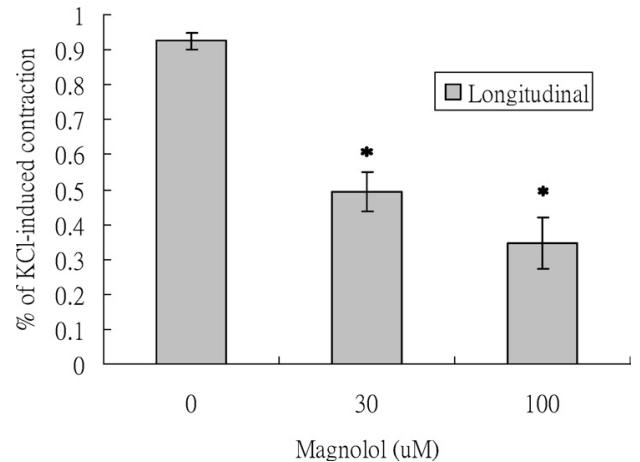

Fig. 5. Inhibitory Effect of Magnolol on KCl-Induced Contraction with the Condition of $1 \mu \mathrm{M}$ Procaine

Magnolol dose-dependently inhibited $40 \mu \mathrm{M} \mathrm{KCl-induced} \mathrm{longitudinal} \mathrm{muscle} \mathrm{con-}$ traction. Data are shown as means \pm S.E. $*$ Significance at $p<0.05 v s .0 \mu \mathrm{M}$ magnolol (blank), $n=8$

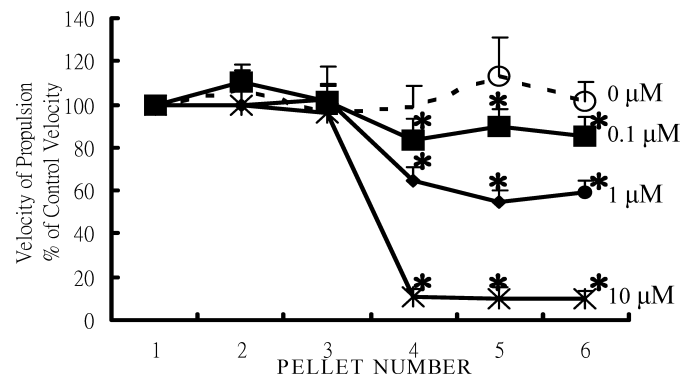

Fig. 6. Inhibitory Effect of Magnolol on Velocity of Pellet Propulsion in Guinea Pig Colon Segments

At the concentration of $0.1-10 \mu \mathrm{M}$, Magnolol diminished the velocity of pellet propulsion in guinea pig colon segments. Data are shown as means \pm S.D. $*$ Significance at $p<0.05 v s .0 \mu \mathrm{M}$ magnolol (blank), $n=6$.

Therefore the mechanism of inhibition on lower gastrointestinal tract smooth muscle is different from that on porcine trachea, which is achieved by blockade of calcium influx through voltage dependent $\mathrm{Ca}^{2+}$ channels only.

It is well known that the coordinated contractions and relaxations of the smooth muscle cells are the basis of gastrointestinal motility. Previous studies showed that the inhibitory effect of MAG on muscle contractions induced by stimulants does not rely on $\beta$-adrenergic- ${ }^{16)}$ and protein Kinase A activity, ${ }^{17)}$ thus, intracellular $\left[\mathrm{Ca}^{2+}\right]_{\mathrm{i}}$ and sensitivity of contractile apparatus to calcium ion may be targets of MAG. Factors that increase $\left[\mathrm{Ca}^{2+}\right]_{\mathrm{I}}$ in visceral smooth muscle cells involve ${ }^{18)}$ 1) influx of $\mathrm{Ca}^{2+}$ through the voltage-operated calcium channel (VOCC), receptor-operated calcium channel (ROCC), antidromic $\mathrm{Na}^{+} / \mathrm{Ca}^{2+}$ exchangers, and so on; 2) release of $\mathrm{Ca}^{2+}$ from the $\mathrm{Ca}^{2+}$ store, mainly from sarcolemmal membrane (SR), and this release takes the form of calcium induced calcium release (CICR) and $\mathrm{InsP}_{3}$-induced $\mathrm{Ca}^{2+}$ release (IICR) (induced by activation of ryanodine receptor and $\operatorname{InsP}_{3}$ receptors); 3) reuptake of $\mathrm{Ca}^{2+}$ into the $\mathrm{SR}$; and 4) extrusion of $\mathrm{Ca}^{2+}$ via $\mathrm{Ca}^{2+}$-ATPase and orthodromic $\mathrm{Na}^{+} / \mathrm{Ca}^{2+}$ exchange. Therefore, these factors affecting the intracellular $\left[\mathrm{Ca}^{2+}\right]_{\mathrm{i}}$ may be the targets related with the mechanism by which MAG influences colon muscle tissue contraction.

It is well known that high $\mathrm{K}^{+}$-induced smooth muscle contractions are mediated by activation of the VOCC. Our results showed that MAG dose-dependently inhibited KCl-induced muscle strips contraction, suggesting MAG blocked the calcium influx through VOCC. It has been reported that MAG can inhibit the porcine trachea smooth muscle contraction, with the possible mechanism being blockade of calcium influx through VOCC. ${ }^{10)}$ Thus, these findings suggest that VOCC may be one target for the inhibitory effect of MAG on smooth muscle.

Whether MAG has any effects on ROCC? In order to discover this puzzle, we tested the effect of MAG on the CChinduced muscle strips contraction. Data showed that 1) $100 \mu \mathrm{M}$ MAG significantly inhibited CCh-induced muscle strips contractions in calcium-containing Krebs-bicarbonate buffer with the inhibition rate 27\%; and 2) MAG significantly inhibited CCh-induced contractions in $\mathrm{Ca}^{2+}$-free buffer with inhibition rate $36 \%$. CCh can induce graded depolarization and/or reduction in action potential of membranes through integrating with muscarinic receptors, thus initiating excitation and contraction of GI tract smooth. ${ }^{19)}$ Our results suggested that MAG can inhibit receptor-operated channel. For two major ionic currents in visceral smooth muscle that permeate several cations exist, one is a receptoroperated nonselective channel, and the other is a hyperpolarization-activated channel. In the process of receptor-operated channels, the GTP binding protein-mediated signal transduction pathway plays a key role. These data indicate that MAG can inhibit the ROCC. Therefore, MAG can inhibit both VOCC and ROCC, thus blocking the influx of calcium through sarcolemmal membrane.

On the other hand, the inhibition of MAG on muscle contraction may not only target on the VOCC and ROCC, inhibition of calcium release from SR may contribute to this inhibitory effect too. This is because that $\mathrm{KCl}$-induced influx of calcium through the sarcolemmal membrane causes the increase of $\left[\mathrm{Ca}^{2+}\right]_{\mathrm{I}}$, and such increase of $\left[\mathrm{Ca}^{2+}\right]_{\mathrm{I}}$ subsequently induces the calcium release from SR. Based on this rationale, the inhibition of MAG on muscle contraction may not only on the VOCC, but another possibility exist, that is inhibition on SR. Whether MAG can inhibit calcium release from SR? In order to discover this, calcium-free buffer was selected to test the effect of MAG on 5-HT- and CCh-induced muscle strips contraction, thus to avoid the extracellular calcium affecting the concentration of calcium in cytosol. The results showed that MAG still dose-dependently inhibited the contractions induced by two activators. These data indicate that MAG can inhibit the calcium release from SR. It is thought that activation of a given receptor, such as $\mathrm{CCh}$ on muscarinic receptor and serotonin on 5-HT receptor, ${ }^{20}$ ) modifies an ionic channel through activation of the receptor's coupled $G$ protein. This may involve ${ }^{18)} 1$ ) direct regulation of ion channels without the synthesis of second messengers (e.g., ROCC), 2) regulation of ion channels through an increase in the $\mathrm{Ca}^{2+}$ concentration in the cytosol via the actions of $\mathrm{InsP}_{3}$ and initiated by activation of $\mathrm{Gq} / 11$ (e.g., $\mathrm{K}^{+}$channels, $\mathrm{Cl}^{-}$channels), or 3 ) regulation of ion channels through an increase or decrease in the amount of cAMP induced via the actions of $\mathrm{Gs}$ or $\mathrm{Gi} / \mathrm{o}$ (e.g., $\mathrm{K}^{+}$channels, $\mathrm{Cl}^{-}$channels). Our results showed that in calcium-free media, MAG still inhibited the muscle strip contraction induced by $\mathrm{CCh}$ and 5HT, indicating that MAG may inhibit the action of $\operatorname{InsP}_{3}$. Previous studies showed 5-HT can cause intracellular calcium release from SR. ${ }^{21,22)}$ Present study documented that MAG decreased 5-HT $(10 \mu \mathrm{M})$-induced contraction in a dose-de- 
pendent manner at concentrations ranging from $1-100 \mu \mathrm{M}$, and also MAG significantly decreased the VPP at the concentration of $0.1-10 \mu \mathrm{M}$, and totally inhibited the pellet propulsion when higher than $30 \mu \mathrm{M}$ concentration. These data mean that blockage of calcium release from SR is another mechanism underlining the inhibitory effect of MAG on colon muscle contractions. Interestingly, 30-100 $\mu \mathrm{M}$ MAG totally inhibited the pellet propulsion in colon segment. Any other mechanisms exist about MAG on pellet propulsion? It is well known that pellet propulsion is controlled by enteric nervous system, smooth muscle contraction, and many intrinsic neurons and neurotransmitters. A propagated peristaltic reflex initiated by muscle stretch or mucosa stimulation mediates the propulsion of colonic contents. The reflex involves sequential activation of sensory neurons coupled via modulatory interneurons to ascending excitatory and descending inhibitory motor neurons. ${ }^{23)}$ Main neurons in the intrinsic nerve circuits that are activated by appropriate stimuli are the intrinsic primary afferent neurons (IPANs). It has been reported that fecal pellets trigger the release of 5-HT, which acts via both $5-\mathrm{HT}_{3}$ and $5-\mathrm{HT}_{4}$ receptors to regulate propulsive activity in guinea pig colon. ${ }^{15)} \mathrm{But}$ further study is necessary to solve the questions whether MAG inhibits the 5-HT release from EC cells, and whether and how MAG affects the binding of MAG on 5-HT receptors.

Our data also showed that MAG significantly inhibited the contraction induced by $40 \mathrm{~mm} \mathrm{KCl}$ between $1-100 \mu \mathrm{M}$ concentrations under the presence of procaine. Procaine is an inhibitor of ryanodine receptors. When ryanodine receptor is blocked, the change of intracellular calcium concentration is mainly due to the influx of extracellular calcium through VOCC and ROCC, and activation of $\mathrm{InsP}_{3}$-medicated calcium release from SR. The inhibitory effects of MAG under the condition of procaine reconfirmed the function of MAG on the VOCC and calcium release mediated through the $\mathrm{InsP}_{3}$-receptor. As for inhibitory rate of MAG on voltage-dependent calcium channel, our data showed that the inhibitory effect was mild. It is well known that nifedipine is a classic antagonist of calcium channels. ${ }^{24,25)}$ Comparing inhibitory rate of nifedipine alone $(92 \%)$ with that of MAG alone $(41 \%)$ on $\mathrm{KCl}$-induced contraction of LMS, we found that MAG inhibited the muscle strips contraction about $41 \%$ at the concentration of $100 \mu \mathrm{M}$, but adding nifedipine with MAG significantly enhanced the inhibitory rate about $30 \%$, up to $71 \%$. This result suggested that the inhibitory effect of $100 \mu \mathrm{M}$ MAG on muscle strips is not mainly through nifedipine-specific receptors. Combining MAG and nifedipine together led higher inhibitory effect than that of MAG alone, but the inhibitory rate lower than that of nifedipine alone, suggested that there may have competition between two agents on blockage of calcium channel.

Limitation Recent investigations ${ }^{26,27)}$ found that smooth muscle tone appears to depend on not only incoming extracellular signals $\left[\mathrm{Ca}^{2+}\right]_{\mathrm{I}}$, but also a network of activating and inhibiting intracellular signals. During the regulation of smooth muscle contraction one key event is the phosphorylation/dephosphorylation of the regulatory light chains of myosin II (rMLC) catalyzed, respectively, by the $\mathrm{Ca}^{2+}$ - and calmodulin-activated myosin light-chain kinase (MLCK) and a type 1 myosin phosphatase. When $\left[\mathrm{Ca}^{2+}\right]_{\mathrm{I}}$ increase, $\mathrm{Ca}^{2+}$ binds to calmodulin and activates MLCK, leading to phosphorylation of rMLC predominantly at Ser-19. Phosphorylation of rMLC allows the myosin ATPase to be activated by actin and then muscle contracts. The activity of MLCP is inhibited by a group of kinases involving Rho-associated kinase, and protein kinase $\mathrm{C}$, leading to an increase in $\mathrm{Ca}^{2+}$ sensitivity. ${ }^{28)}$ ROCKs (which are also known as Rho kinases) are the first group effectors of Rho to be discovered, and were initially characterized for their roles in mediating the formation of RhoA-induced stress fibres and focal adhesions through their effects on the phosphorylation of myosin light chain (MLC). ${ }^{29)}$ In our study, we have not investigated whether MAG affected the network of activating and inhibiting intracellular signals, especially about the phosphorylation/dephosphorylation of rMLC and subsequent events. Further studies will help to clarify the detailed mechanism of MAG on muscle contraction.

\section{CONCLUSION}

Taken together, our results show that MAG is able to inhibit colon muscle contractions. The mechanism of inhibitory effect of MAG involves, at least, blockage the calcium influx through VOCC and ROCC, and inhibition of calcium release from SR. This result explains the therapeutic effects of Cortex magnoliae officinalis on lower gastrointestinal disease.

Acknowledgements This work is supported by the Faculty Research Grant, Hong Kong Baptist University. And authors want to thank Dr. Martha Dahlen for her assistance in editing of English writing of this paper.

\section{REFERENCES}

1) Zhang G. D., Zhongguo Zhong Yao Za Zhi, 14, 565—568, 576 (1989).

2) Chen Q. S., "Pharmacology and Applications of Chinese Material Media," Vol. 2, ed. by Chang H. M., But P. P. H., World Scientific Singapore, 1986, pp. 878-880.

3) Wang J. P., Hsu M. F., Raung S. L., Chang L. C., Tsao L. T., Lin P. L., Chen C. C., J. Pharm. Pharmacol., 51, 285-294 (1999).

4) Son H. J., Lee H. J., Yun-Choi S. H., Ryu J. H., Planta Med., 66, 469-471 (2000).

5) Chiu J. H., Wang J. C., Lui W. Y., Wu C. W., Hong C. Y., J. Surg. Res., 82, 11-16 (1999).

6) Lee M. M., Hseih M. T., Kuo J. S., Yeh F. T., Huang H. M., Neuroreport, 9, 3451-3456 (1998).

7) Haraguchi H., Ishikawa H., Shirataki N., Fukuda A., J. Pharm. Pharmacol., 49, 209-212 (1997).

8) Shen Y. C., Sung Y. J., Chen C. F., Eur. J. Pharmacol., 343, 79-86 (1998).

9) Kong C. W., Tsai K., Chin J. H., Chan W. L., Hong C. Y., Shock, 13 $24-28$ (2000).

10) Ko C. H., Chen H. H., Lin Y. R., Chan M. H., Planta Medica, 69, $532-536$ (2003).

11) Zhang W. W., Li Y., Wang X. Q., Tian F., Cao H., Wang M. W., Sun Q. S., World J. Gastroenterol., 11, 4414-4418 (2005).

12) Sarna S. K., Gastroenterology, 89, 894-913 (1985).

13) Davis G. R., Santa Ana C. A., Morawski S. G., Fordtran J. S., Gastroenterology, 83, 844-850 (1982).

14) Forrest A., Molleman A., Parsons M., Euro. J. Pharmacol., 509, 77783 (2005).

15) Jin J. G., Foxx-Orenstein A. E., Grider J. R., J. Pharmacol. Exp. Ther, 288, 93-97 (1999).

16) Tsai T. H., Lee T. F., Chen C. F., Wang L. C., Neurosci. Lett., 186, $49-52(1995)$. 
17) Wang J. P., Hu M. F., Raung S. L., Chang L. C., Tsao L. T., Lin P. L., Chen C. C., J. Pharm. Pharmacol., 51, 285-294 (1999).

18) Kuriyama H., Kitamura K., Itoh T., Inoue R., Physiol. Rev., 78, 811920 (1998)

19) So I., Kim K. W., J. Smooth Muscle Res., 39, 231-247 (2003).

20) Berridge M. J., Bootman M. D., Roderick H. L., Nat. Rev. Mol. Cell. Biol., 4, 517-529 (2003).

21) Inoue R., Isenberg G., Am. J. Physiol., 258, C1173 - C1178 (1990).

22) Nilius B., Droogmans G., Physiol. Rev., 81, 1415-1459 (2001).

23) Foxx-Orenstein A. E., Grider J. R., Am. J. Physiol., 271 (3 Pt 1), G433-G437 (1996).
24) Hering S., Beech D. J., Bolton T. B., Lim S. P., Pflugers Archiv., 411, 590-592 (1988).

25) Advenier C., Cerrina J., Duroux P., Floch A., Renier A., Br. J. Pharmacol., 82, 727-733 (1984).

26) Leung T., Chen X. Q., Manser E., Lim L., Mol. Cell. Biol., 16, $5313-$ 5327 (1996).

27) Somlyo A. P., Somlyo A. V., J. Physiol., 522, 177-185 (2000).

28) Pfitzer G., J. Appl. Physiol., 91, 497-503 (2001).

29) Riento K., Ridley A. J., Nat. Rev. Mol. Cell. Biol., 4, 446- 456 (2003). 